\title{
Evolution and functions of human dance
}

\author{
Bernhard Fink $^{\text {a,b, }}$, Bettina Bläsing ${ }^{c}$, Andrea Ravignani ${ }^{\mathrm{d}}$, Todd K. Shackelford ${ }^{\mathrm{e}}$ \\ ${ }^{a}$ University of Vienna, Department of Evolutionary Anthropology, Althanstraße 14, 1090 Vienna, Austria \\ ${ }^{\mathrm{b}}$ Biosocial Science Information, Ortsstraße 63, 2362 Biedermannsdorf, Austria \\ ${ }^{\mathrm{c}}$ Technical University of Dortmund, Faculty of Rehabilitation Science, Department of Music and Movement in Rehabilitation and Therapy, Emil-Figge-Straße 50, 44227 \\ Dortmund, Germany \\ d Comparative Bioacoustics Group, Max Planck Institute for Psycholinguistics, Wundtlaan 1, 6525, XD, Nijmegen, the Netherlands \\ ${ }^{\mathrm{e}}$ Departement of Psychology, Oakland University, Rochester, MI, USA
}

\section{A R T I C L E I N F O}

\section{Keywords:}

Dance

Human

Evolution

Social interaction

Signaling

\begin{abstract}
A B S T R A C T
Dance is ubiquitous among humans and has received attention from several disciplines. Ethnographic documentation suggests that dance has a signaling function in social interaction. It can influence mate preferences and facilitate social bonds. Research has provided insights into the proximate mechanisms of dance, individually or when dancing with partners or in groups. Here, we review dance research from an evolutionary perspective. We propose that human dance evolved from ordinary (non-communicative) movements to communicate socially relevant information accurately. The need for accurate social signaling may have accompanied increases in group size and population density. Because of its complexity in production and display, dance may have evolved as a vehicle for expressing social and cultural information. Mating-related qualities and motives may have been the predominant information derived from individual dance movements, whereas group dance offers the opportunity for the exchange of socially relevant content, for coordinating actions among group members, for signaling coalitional strength, and for stabilizing group structures. We conclude that, despite the cultural diversity in dance movements and contexts, the primary communicative functions of dance may be the same across societies.
\end{abstract}

\section{Introduction}

Dance is a multisensory experience that typically includes sight, sound, touch, and smell, in addition to proprioceptive and vestibular sensations. It can be performed alone or with others. According to Hanna and colleagues, purposeful, intentionally rhythmical, and culturally patterned body movements other than ordinary motor activities characterize dance (Hanna, 1987, 2010; Hanna et al., 1979). Dance is universally performed (Hanna, 1987; Kurath, 1960), but the understanding of what it includes is shaped by cultural context. Music often accompanies dance and although dance movement is often linked to a rhythmic pattern or trigger, whether music is a determining factor is debated. In contemporary dance, for example, movement is often choreographed to be performed in the absence of music or any acoustic or rhythmic information (Waterhouse, Watts, \& Bläsing, 2014). Much evidence, however, indicates that music and dance evolved together, leading to the suggestion that dance is a component of human musicality (Fitch, 2015, 2016).

The study of dance is often limited to a particular setting in a given society in that it considers social and cultural information transmitted through symbols and meanings for a particular space-time entity (Siegfried, 1988; Vicary, Sperling, Zimmermann, Richardson, \& Orgs, 2017). Moreover, previous biological accounts of dance have primarily addressed questions of mechanisms and development (Christensen, Cela-Conde, \& Gomila, 2017; Fitch, 2016; Laland, Wilkins, \& Clayton, 2016; Ravignani \& Cook, 2016). We contend that to understand why human dance evolved, a functional approach must address the nature of dance-related behavior, thus considering evolutionary explanations in a Darwinian sense. Likewise, it is important to address why dance is performed across societies. A ubiquitous phenomenon likely has functional relevance not just for a given society or setting but for the entire species.

In this article, we address the evolutionary functions of human dance and its roles in society. We focus on the motivations from which dance might have evolved in human cultures but we do not consider aspects of dance as an art form - this would go beyond the goals of this article. We discuss research investigating mating-related qualities conveyed through dance-a topic that has received recent attention (see Fink,

\footnotetext{
* Corresponding author at: University of Vienna, Department of Evolutionary Anthropology, Althanstraße 14, 1090 Vienna, Austria.

E-mail address: bfink@gwdg.de (B. Fink).
} 
Weege, Neave, Pham, \& Shackelford, 2015; Fink, Weege, Neave, Ried, \& do Lago, 2014; Hugill, Fink, \& Neave, 2010). We focus on the mechanisms and causation of dance, which may not be limited to human culture and capacities but have analogs in other species. This includes evidence of the role of ritualistic processes in animals and humans, proximate and ultimate mechanisms of inter-individual coordination (e. g., behavioral synchrony), and the roles of music and rhythm. We review evidence for the significance of dance in group cohesion, the signaling of coalitional strength, and the assessment of social information and social bonding. We propose that human dance evolved from ordinary (noncommunicative) movements to communicate socially relevant information accurately. We conclude with suggestions for future research.

\section{Is dance adaptive or a byproduct?}

From an adaptationist perspective, a key issue in the study of human dance is its fitness benefits, either for an individual or a group of individuals. At the individual level, "good" dancing skills may be beneficial in attracting mating partners, as observed in many animals during courtship. However, mating-related motives alone cannot explain the diversity of human dance in expression and where (or among whom) it occurs. Thus, alternative hypotheses have been proposed that focus on dancing in groups by emphasizing the importance of synchronization with group members. Independent of the level at which dance may be considered an adaptation, the question remains regarding its functional benefits. Dance also could be a byproduct that emerged incidentally in the course of other evolutionary processes. Similar concern has been raised about hypotheses for the evolution of music ("auditory cheesecake"; Pinker, 1997). Several criteria together suggest that music is not a byproduct of other traits (Mehr, Krasnow, Bryant, \& Hagen, 2020; Miller, 2000) but offers certain benefits to individuals that engage with and express it. The arguments apply also to human dance. The earliest documentation of dancing includes drawings in the Magura cave (Bulgaria) and the Bhimbetka rock painting (India) 10,000 years ago (Lange, 1975; Sachs, 1937). However, to address dance origins and functions as a product of selection processes, a detailed account of its prehistory is not necessary (as Miller, 2000, notes for music). Psychological adaptations do not leave a fossil record, and the human fossil record itself has gaps that may lead to unjustified speculations about the origin of behaviors. Thus, in addressing whether dance is an adaptation, it is more important to consider current evidence, within humans and across taxa, to identify a biological function.

Dance is observed across cultures and historical epochs. Although there is considerable variation in dance quality (e.g., how attractive or skillful a dancer is perceived), all humans have the capacity to dance. This capacity is present before sexual maturity, as dance movements can be performed alone or in a group by children and adults without extensive training. As with music (and language), specific neural mechanisms underlie the perception and production of dance (Bläsing et al., 2012). The structure of human dance is complex (Charnavel, 2019), especially regarding the coordination of dance movements with others. Similarly, humans can identify structures in dance and use them in assessments of the dancer, although an assessor may not be aware of the causes of their assessments. Finally, the comparative study of "dance" in humans and non-human animals reveals analogs, suggesting convergent evolution of dance(-like) movements. One example is the elaborate and vigorous courtship displays in birds (and see below). However, there are also Koehler's early observations of chimpanzees in captivity, which suggested primitive stages of dancing including pirouetting or spinning around an axis and semi-rhythmic movement of a chimpanzee group (Francis, 1991; Sachs, 1937). Collectively, these considerations suggest that dance is unlikely to reflect the incidental emergence of behavior with no evolved function.

\section{Dance and mating-related motives}

Research on the communicative function of dance in the mating context has focused on sensitivity to variation in the individual performance of non-trained dancers during spontaneous free dancing. Sexual Strategies Theory (Buss \& Schmitt, 1993) proposes that men and women have evolved different preferences and strategies in response to sexspecific adaptive problems of mate selection. This theory has successfully predicted sex differences in sexual psychology and behavior, including attraction to and signaling of mating-related qualities (for review, see Buss \& Schmitt, 2019). Research has documented sexspecific facial, bodily, and vocal indicators that men and women include in assessments of potential mates (Grammer, Fink, Møller, \& Thornhill, 2003; Little, Jones, \& DeBruine, 2011; Pisanski \& Feinberg, 2019). Thus, studies investigating the perception of dance in the mating context have suggested that sex-specific information about an individual's quality is evident in dance movements.

\subsection{Male dance movements}

"Good" male dancers receive greater visual attention and women judge them to be more attractive and masculine than "bad" male dancers (Weege, Lange, \& Fink, 2012). Likewise, the dances of physically stronger men (but not women; Weege, Pham, Shackelford \& Fink, 2015) are judged more attractive (Hugill, Fink, Neave, \& Seydel, 2009; McCarty, Hönekopp, Neave, Caplan, \& Fink, 2013). Physical strength predicts gender identification from dance movements in adults but not children (Hufschmidt et al., 2015), suggesting that the assessment of physical strength from dance becomes relevant for individuals only of reproductive age. Thus, male physical strength may be one of the mating-related qualities conveyed through dance movements, and women, in particular, make attributions about such qualities using information displayed in men's dance movements, similar to the findings of associations of physical strength and assessments of male facial and body morphology (Fink, Neave, \& Seydel, 2007; Sell, Lukazsweski, \& Townsley, 2017; Windhager, Schaefer, \& Fink, 2011). Physically stronger male dancers may be preferred because their movements indicate personality characteristics that facilitate acquiring and/or maintaining status.

Male risk-taking, especially in young adulthood, reflects competitiveness, and studies have documented a female preference for men willing to accept certain risks (Apalkova et al., 2018) and consider these men attractive (Henderson et al., 2005). There is evidence for a positive relationship between men's risk-taking behavior and women's assessments of men's dance attractiveness (Hugill, Fink, Neave, Besson, \& Bunse, 2011). Other research on dance and personality characteristics showed that women were not able to accurately assess men's personality from their dance movements (Weege, Barges, Pham, Shackelford, \& Fink, 2015)_a result that corroborates research investigating relationships of self-reported personality with observer-reports of personality based on gait (Thoresen, Vuong, \& Atkinson, 2012). However, a negative correlation of men's (self-reported) neuroticism with women's assessments of their dance attractiveness suggested that certain kinematic characteristics (speed, amplitude, and velocity) might affect perceptions of dance such that people who associate elements of dance performance with desirable personality traits also rate that dance as more attractive. A dancer who displays faster movements, performed with higher velocity and lower amplitude, may be judged higher on neuroticism compared with a dancer who performs the movements with lower velocity and higher amplitude. Variation in kinematic characteristics is sufficient to cause social attributions (Barrett, Todd, Miller, \& Blythe, 2005; Dittrich \& Lea, 1994; Runeson \& Frykholm, 1983) despite the absence of explicit social context (Heider \& Simmel, 1944). Moreover, biological motion information (as produced by point-light displays) is sufficient to assess the emotional state of a dancer (Dittrich, Troscianko, Lea, \& Morgan, 1996; Walk \& Homan, 1984). Thus, certain kinematic 
characteristics of body movement provide socially relevant information. A biomechanical analysis of male dance movements (as displayed by virtual characters animated with motion-captured movements of nonprofessional dancers) documented that women preferred dancers who displayed larger and more variable bending and twisting movements of their head/neck and torso, and faster bending and twisting movements of their right knee (Neave et al., 2011). The authors suggested that these kinematic qualities characterize vigorous and skilled males and that women use these features to obtain information about male physical condition.

Evidence about the significance of motor skills in mating has been collected in many animals - from insects to vertebrates (Byers, Hebets, \& Podos, 2010; Fusani, Barske, Day, Fuxjager, \& Schlinger, 2014; Soma \& Iwama, 2017; Ullrich, Norton, \& Scharff, 2016). For example, male golden-collard manakins (Manacus vitellinus) perform elaborate, acrobatic courtship rituals and females prefer males that perform moves at greater speed (Barske, Schlinger, Wikelski, \& Fusani, 2011). Moreover, telemetric recordings of heart rate showed that more elaborate courtship movements predict larger metabolic investment. Similar mechanisms may apply to humans. Elaborate dance movements are challenging actions that require a high level of coordination, and only individuals with the relevant physical and neural skills can perform them. Because "good" dancing is not only artistic and appealing but also energetically demanding, we hypothesize that women will rate dances of men in better physical condition to be more attractive than dances of men in poorer physical condition. This hypothesis could be tested by collecting male dance movements with, for example, motion capture, in addition to securing information about dancers' physical condition in challenging contexts, to then investigate relationships with dance preference measures.

\subsection{Female dance movements}

Studies investigating the signaling quality of male dance suggest that dance movements convey information about vigor and strength-qualities that affect both women's and men's social perceptions. However, less research has investigated the signaling quality of female dance (for review, see Hugill et al., 2010; Fink et al., 2014). Attractive female dancers receive greater visual attention than less attractive female dancers, and men's visual attention correlates positively with their (subsequent) judgments of attractiveness, femininity, and dance movement "harmony" (Roeder et al., 2015). One explanation for these findings is that visual cues of female quality influence men's assessments of women's dance movements. Research has documented behavioral as well as visual, olfactory, and vocal cues to female fertility (Thornhill \& Gangestad, 2008). Thus, women's dance movements may provide information about their fertility. Female lap dancers, for example, reported higher earnings on higher fertility days (Miller, Tybur, \& Jordan, 2007). It is unclear which specific cycle changes cause the alteration in men's responses, although it is likely a combination of hormonemediated behavioral and sensory changes that accompany periods of high and low fertility. In a laboratory study (Fink, Hugill, \& Lange, 2012), men rated women's dances and gaits recorded in the fertile phase higher on attractiveness than those recorded in the non-fertile phase. Thus, men may be perceptually sensitive to female fertility encoded in body movements. Whether specific movements evolved as a signal to facilitate women's ancestral reproductive success remains to be investigated. Some scholars (e.g., Gangestad \& Thornhill, 2008) have argued that this is unlikely and suggest that men's sensitivity to female fertility cues reflect male adaptations that detect byproducts of physiological changes associated with female fertility (e.g., changes in estrogen levels).

A recent biomechanical analysis of female dance movements (McCarty et al., 2017) documented that three types of movement contributed independently to positive assessments of female dance: greater hip swing, more asymmetric thigh movements, and intermediate levels of asymmetric arm movements. Asymmetric arm movements may express high-quality motor control because it is more challenging to perform different movements than the same movement in two limbs simultaneously. When making dance quality judgments, several movement configurations result in the same dance rating. Especially in a cross-cultural context, the meaning of particular movements may be different due to society-specific connotations. However, we suggest that this is not the case for the fundamental kinematic properties of these movements. That is, although individuals in different societies or cultures may use different dance movements in different contexts, the kinematic characteristics of dance movements convey biologically credible information about individual differences. Therefore, the investigation of universalities in the social significance of dance movements should consider body kinematics in addition to documentation of cultural diversity in dance performance. This approach may reveal similarities in movement quality across societies and cultures and, from a comparative perspective, across taxa (e.g., the rhythmic display of vigor and strength; Lorenz, 1952; Grammer, Keki, Striebel, Atzmueller, \& Fink, 2003; Neave et al., 2011).

Considering recent research on the perception of male and female solo dances of untrained dancers together, the findings are consistent with the suggestion that sex-specific individual qualities are conveyed through dance performance. Whether from the perspective of the dancer this is intentional is less clear. Observers are sensitive to variation as they distinguish "good" from "bad" dancers (e.g., Neave et al., 2011) or express a preference for dancers that signal superior reproductive quality (e.g., Fink et al., 2012; Miller et al., 2007). We do not know whether good dance performance correlates with higher reproductive success. A study assessing male and female dancing skills objectively (e. g., through motion-capturing) and relating these positively to quantitative measures of reproduction would provide support for the hypothesis that certain kinematic characteristics facilitate reproduction in addition to being perceived as attractive. Maasai men, for example, are known for their participation in jumping dances (Refsdal, 2017). These dances are a competitive ritual in which junior warriors demonstrate physical skills to women. Higher and more graceful jumps are perceived as more appealing. Maasai women sing and dance too, thus getting closer to the men and indicating their interest through movement. The ritual is an important part of the Maasai lifestyle as it facilitates the arrangement of marriages (Århem, 1985). Comparing the Maasai ritualized jumping dances with settings in Western societies may be difficult, in part because the continuous practice of the Maasai ritual spans several days. On the other hand, it might be useful to consider the social significance of dance in several social settings, from night clubs to more ritualized forms of dance at social gatherings and weddings as these settings may fulfill the function of exchanging accurate social information.

\section{Dance and ritualized communication}

\subsection{Ritualized communication}

According to Huxley (1966), ritualization is the canalization of emotionally motivated behavior designed to i) promote unambiguous signaling, both intra- and inter-specifically, ii) serve as stimulators or releasers of more efficient patterns of action in other individuals, iii) reduce intra-specific damage, and iv) serve as sexual and social bonding mechanisms. Huxley noted two divergent tendencies operating in nonhuman animal ritualization. One is for ritualized behavior to evolve in the direction of a stereotyped response, and the other is to produce ceremonies with a sexual or social bonding function. During vertebrate phylogeny, ritualization tended towards more effective bonding, with more elaborate ceremonies, in which individual learning plays an increasing role, notably in primates (Huxley, 1966). Ritualized nonhuman animal behavior foreshadows several human characteristics, especially concerning rank organization, play, and even primitive 
"dances" (as observed in chimpanzees; Laver, 1964). Although nonhuman primates may display elements of dance patterns, certain of these characteristics are realized only in humans as differences occur in symbolization, emotional expression, and the use of syntactically novel forms without training (Katz, 1976; Hanna et al., 1979). Due to greater cognitive capacity, humans make cross-modal connections, which affords sophisticated symbolism. Ritualized communication is observed in many animals; but the capacity to voluntarily alter symbolic meaning through movement patterns, and thus deliberately express (or withhold) meaning, seems to be unique to humans.

One of the functions of ritualization is the canalization of aggression, such that ritualized behavior provides the opportunity to aggress without risking damage either to oneself or group members. Greeting ceremonies, for example, in humans and other species have this function (Eibl-Eibesfeldt, 1984; Lorenz, 1966). Through its communicative function, dance also may be performed to reduce intra-specific damage. There is evidence that coordinated dance strengthens social bonds (but see Hagen \& Bryant, 2003), and that this has positive effects on the physiology of the dancers and their assessment of the quality of social bonds (Reddish, Fischer, \& Bulbulia, 2013; Tarr, Launay, \& Dunbar, 2014).

\subsection{Signaling accuracy}

Another characteristic of ritualized behavior is that-compared with non-ritualized components-movement, visual, and auditory elements are exaggerated (as in most courtship and territorial defense displays), whereas those serving the original function are reduced (Lorenz, 1966). Zahavi (1980) suggested that a ritualized movement might increase the information relevant to the message encoded in the signal by increasing the reliability of informational transmission. In this view, the signal is a byproduct of selection for reliably transmitted information. A reliable signal must afford the expression of relevant individual differences. Stereotypic signals may be less ambiguous, but they also provide less information about the signaler, which may be compensated by variance in the duration or intensity of the signal (Morris, 1957). Mimic exaggeration, repetition, and typical intensity are marked in most human ceremonies (Eibl-Eibesfeldt, 1984; Lorenz, 1966), and kinematic characteristics mark human ceremonial behavior. In the evolution of communication, it is typically the receiver who exerts selective pressure on the signaler for the evolution of a particular sending mechanism (Maynard-Smith \& Harper, 2003). Although acknowledging that the motivations for human dancing are different from the motivations for instinctive motor patterns due to phyletic ritualization, Lorenz (1966) contended that their effects on social behavior are similar. This applies to ritualized ceremonies (such as group dance), but also to subtle everyday behavior.

Dance can be highly variable in the way it is performed, either individually or collectively (Lange, 1975; Sachs, 1937). In addition to the joint signal or message provided in group performance (e.g., a signal of cohesion and power), there are individual differences in dance quality and motivation, which may provide additional information to group members. These differences may have important functions in social communication. In non-human animals, the communicative function of certain movements is thought to have evolved from common motor patterns through ritualization (Halina, Rossano, \& Tomasello, 2013; Scott et al., 2010). Whether this suggestion can be applied to the origin of human dance is unclear. However, we consider it plausible that for both the signaler and receiver, collecting credible social information from the observation of conspecifics' movements had a significant impact on the origin of dancing. Static representations of the face and body, for example, provide information about an individuals' mating quality, and this can influence mating decisions (Grammer, Fink, et al., 2003). This information can be noisy, or an individual can manipulate traits evolved to signal certain information and thus deceive others by faking quality information. In contrast, the information conveyed through body movement, either actively or passively, seems to be a more reliable source of information, because of the complexity of the display. Dancing can be difficult to produce, especially when it requires coordination with other dancers or when it is intended to be appealing (e.g., for the opposite sex), and may therefore convey fundamental social information across societies.

\subsection{Body "language"}

Due to the significance of kinematic information for group members, structured settings for dance may better qualify for this mode of information exchange. The increasing size of human groups and social networks over evolutionary history may have imposed selection pressures causing the evolution of a communication system based on the movement of the whole body. Such communication works even in large groups, beyond the limitations of face-to-face communication. Thus, dance may have evolved from body "language" and gesture as a vector for the communication of social information because it conveyed signals that are less susceptible to deception than, for example, verbal information. It might also have served initially to communicate affective and emotional states rather than semantic information, in a way that can be understood implicitly.

Evidence from neurobiological studies suggests that the ability to produce and perceive basic categories of emotional body language solved adaptive problems recurrent over human evolutionary history (De Gelder, 2006), given identification of mechanisms that involve neural resources that facilitate perception of facial expressions of emotions (see for review, De Gelder, 2006). A fearful face signals threat; however, fearful body postures or movements provide additional information that specifies the source of the threat and thus the intention of the individual displaying the emotion. We contend that the combined presence of physical appearance, facial expressions, and body movement offers greater assessment accuracy in social settings than each of these features alone. This applies to threat perception but may extend to the assessment of many social qualities, including coalitional quality and mating-related motives. Because of the fundamental correspondences between bodily actions and linguistic functions, Sandler (2018) proposes that the recruitment and composition of body actions provide evidence for key properties of language and its emergence. Much of spoken language can be deceptive whereas "compositional communication"-including body actions-may be less so (for evidence on the use of multiple cues, see Candolin, 2003).

\section{Dancing in groups}

Dance is often performed with others, either planned (e.g., in a purposeful group performance) or spontaneously (e.g., in a nightclub). Especially the former typically requires coordination between dancers and, therefore, relies on preparation, whereas in the latter setting free movements are adjusted spontaneously to an external rhythm or musical beat. Joint dance performance in which the individual does not expose him/herself but rather "disappears" in the group may fulfill important social functions in addition to the assessment of individual dancing ability, as it can strengthen social cohesion (Dunbar, 2012; Reddish et al., 2013) and communicate this to observers (Hagen \& Bryant, 2003). At the proximate level, interpersonal coordination of movement is an elementary characteristic of group dance. Phillips-Silver and Keller (2012) refer to coordination as occurring when movements between coactors are coupled in a synchronized or complementary fashion. Coordination is thus viewed as a basic principle of human interaction in social contexts.

\subsection{Movement synchronization}

Group synchrony results in shared social experiences reflected in coordinated physiological responses (Konvalinka et al., 2011; Müiller \& 
Lindenberger, 2011) and cortical activity (Hasson, Nir, Levy, Fuhrmann, \& Malach, 2004). Most of these studies were conducted in laboratory settings that may not reflect the complexity of real-life interactions. A recent study documented movement synchrony through recordings of accelerometry data across a large number of participants dancing in a club (Ellamil, Berson, Wong, Buckley, \& Margulies, 2016). Synchrony of torso movement was associated with pulsations which approximate walking rhythm. Moreover, songs played with greater frequency facilitated greater group synchrony; thus, group synchrony may be constrained by the familiarity of movement and music (or rhythm). Moving in synchrony, however, also influences social and emotional parameters in the absence of music or an external beat. Zimmermann, Vicary, Sperling, Orgs, and Richardson (2018) showed that personal affiliation can arise from distributed coordination between group members (i.e., a network of coupled group members moving in synchronized dyads), rather than from unitary synchrony (all group members moving in unison, in time with each other, to a common rhythm). Participants were assigned different choreographic tasks that facilitated either individual non-synchronized or coordinated synchronous movement, without instruction about how the latter was to be achieved. Synchrony was reached via less specific task instructions and in the absence of an external rhythm, leading to the conclusion that the mechanisms through which synchrony is established determine the influence of synchrony on affiliation and conformity between group members.

Given the difficulty of disentangling cause and effect in dynamic group settings in which synchronization is accompanied by music or rhythm, the "silent-disco" paradigm has been a useful approach for investigating physiological and psychological changes related to synchrony, as such effects can be attributed to behavioral synchrony of dancing. Tarr, Launay, and Dunbar (2016) collected information on pain threshold and perceived social closeness of men and women who received auditory instructions (via headphones) and listened to music tracks, either in synchrony, partial synchrony, or asynchrony with previously learned movements. In the synchrony condition, dance movements increased perceived social closeness and pain thresholds. These effects were observed when participants synchronized with each other and the music but were not observed in partial synchrony or asynchrony conditions. Previous studies reported a relationship between pain threshold and activation of the endogenous opioid system (Dunbar, Kaskatis, MacDonald, \& Barra, 2012; Tarr et al., 2014). Thus, dancing in synchrony may facilitate social bonding by stimulating the production of endorphins, and may facilitate social closeness between strangers (Tarr et al., 2016). Dancing does not have to involve matching body movements with others and in time with the music; however, there seems to be a physiological benefit from synchronizing movements among group members who dance together, in addition to facilitating social cohesion. Dancing together may have been collectively advantageous insofar as it facilitated and maintained social closeness (Dunbar \& Schultz, 2010; Tarr et al., 2016).

\subsection{Dancing and entrainment}

Movement synchronization is often attributed to the ability of humans (and other species, see, e.g., Laland et al., 2016; cf. Ravignani \& Cook, 2016) to entrain to perceived (rhythmic) stimuli. Rhythm and timing are particularly important dimensions (Ravignani \& Kotz, 2017; Schirmer, Meck, \& Penney, 2016), as they enable precise synchrony (intended as fine-grained temporal co-occurrence; Ravignani, 2017), role switching (Pika, Wilkinson, Kendrick, \& Vernes, 2018; Ravignani, Bowling, \& Fitch, 2014), turn-taking, and other interactive coordination patterns (Waterhouse et al., 2014) based on human entrainment. Two partly contrasting hypotheses have been advanced to explain the role of rhythmic capacities in the evolution of dance. Whereas one hypothesis emphasizes the importance of an individual's capacities for imitation and motor sequencing (Laland et al., 2016), the other focuses on the relevance of audio-motor timing abilities and propensity for interactive signaling (Ravignani \& Cook, 2016). No matter the particular hypothesis, mapping similarities between group rhythms in non-human animals (Ravignani et al., 2014; Ravignani \& Cook, 2016) and human dance may reveal evolutionary homologies and analogies of rhythmic behaviors underlying dance.

Phillips-Silver, Aktipis and Bryant (2010) observed that entrainment is predicated on the ability to perceive and produce rhythmic action and real-time integration between sensory and motor systems. The authors highlight that entrainment often occurs in more complicated contexts than with an isochronous pulse, to a wide range of tempi, and that it involves sensorimotor activity across multiple modalities. Clayton (2012) and Phillips-Silver et al. differentiate between self-entrainment (intra-individual) within a particular individual as the coordination of body parts, mutual entrainment (inter-individual) between two individuals, and social entrainment within (intra-group) or between (inter-group) groups. Examples include entrainment of body sway during a conversation (e.g., Fowler, Richardson, Marsh, \& Shockley, 2008; Shockley, Baker, Richardson, \& Fowler, 2007; Shockley, Santana, \& Fowler, 2003) or of stepping patterns while walking together (e.g., Miles, Nind, \& Macrae, 2009; van Ulzen, Lamoth, Daffertshofer, Semin, \& Beek, 2008). Phillips-Silver and Keller (2012) suggest that the roots of entrainment might be developed in infancy via mimesis with a caretaker, and propose temporal and affective components of entrainment, the latter involving interpersonal bonds as well as the pleasure associated with moving in time with others. The influence of movement on rhythm perception develops in infancy; thus, passive movements acting on the vestibular system (e.g., being rocked or bounced) influence metrical interpretations (Philips-Silver \& Trainor, 2005). Rhythm perception and movement are strongly linked in human brain processing (Chen, Penhune, \& Zatorre, 2008; Grahn \& Brett, 2007; Patel \& Iversen, 2014) and behavior, in particular in the coordination of joint actions. Knoblich and Sebanz (2008) note that especially in music, dance, and sports, joint action depends on inter-individual entrainment, which is based on and interacts with shared intentionality (specifically, to synchronize).

\subsection{Shared intentionality}

Ellamil et al. (2016) suggested that shared intentionality arising from music familiarity promotes the synchronization of movement in groups. That is, common performance goals and knowledge of the musical structure and intentions of co-performers may facilitate the coordination of joint actions. However, the authors note that it is unclear whether the resulting movement synchrony leads to social bonding, or whether social bonding from shared intentionality leads to movement synchrony. According to Witek, Clarke, Wallentin, Kringelbach, and Vuust (2014), structural and acoustic properties of music are important in promoting pleasurable sensorimotor synchronization. Syncopation-a feature of rhythmic complexity violating listener's metric expectations-shows an inverted U-shaped relationship with ratings of wanting to move and feelings of pleasure (Witek et al., 2014); that is, intermediate degrees of syncopation elicited the most positive response, perhaps because they contain sufficient rhythmic complexity for stimulation, but not so much as to prevent entrainment. These ratings were corroborated by people's reported experience with dancing but were not affected by musical training or familiarity with groove (but see Hannon, Soley, \& Ullal, 2012, for a culture-specific response to syncopation).

\subsection{Coalitional strength}

Hagen and Bryant (2003) suggested that, in addition to promoting group cohesion, synchrony in group dance may provide information about coalitional strength (e.g., to defend territory). Group cohesion may facilitate the exchange of credible information among members about the benefits they can share. Coalitional quality is one such feature, and it is likely that in ancestral environments there was selection on 
members of coalitions to assess coalitional qualities of others and to communicate solidarity and coalitional strength to observers. For example, men who walk synchronously with a male confederate envision an antagonist as less physically formidable than men who walked asynchronously with a male confederate (Fessler \& Holbrook, 2014). Hagen and Bryant argued that dance (and music; see also Mehr et al., 2020) are credible signals of coalitional quality because they are complex and require considerable time and effort to compose and practice. Thus, long-established coalitions are expected to display more sophisticated performances and greater synchrony. Group performance can provide credible information of collective interest, including signaling of emotions or mating-related qualities in addition to coalitional strength. Group dance generates benefits over other activities in that it is particularly useful in providing social information to group members. First, many members of a group are present at the same time and, therefore, gathering information about others is less time consuming than, for example, in dyadic social exchange. Moreover, group settings afford direct comparison of quality information displayed by members. Second, group performance can be challenging for individuals. Participating in joint performance requires coordination with co-actors and this may put additional pressure on the individual performer; individuals differ in their capacity and skills, and these differences are likely to be evidenced with increasing complexity of the performance. Thus, individual differences in dance performance may accurately convey information about an individual's stamina and motivation, and test social bonds (Zahavi \& Zahavi, 1997) rather than directly causing them (Hagen \& Bryant, 2003; Mehr et al., 2020).

\section{Dance and genetics}

Genetic influences on the "dance phenotype" have received little attention in research on human dancing. Bachner-Melman et al. (2005) suggested that two polymorphic genes contribute to artistic creativity: the arginine vasopressin 1a receptor (AVPR1a) and the serotonin transporter (SLC6A4). AVPR1a could contribute to the dance phenotype given its role in affiliative, social, and courtship behavior across vertebrates (Insel and Young, 2001). Serotonin plays a role in human "spiritual" experiences (Borg, Andrée, Soderstrom, \& Farde, 2003); thus, Bachner-Melman et al. (2005) argued that SLC64A might be linked to dancing, given that spirituality and/or altered states of consciousness are often observed in dancing (dancers also scored higher on a selfreport individual difference variable that correlates positively with spirituality and altered states of consciousness).

Moreover, the epistasis of the two genes might play a role in enhancing the communicative function of dance, given such effects in the hypothalamic control of communicative behavior (Albers, Karom, \& Smith, 2002). The combination of both polymorphic genes is overrepresented in dancers and may, therefore, contribute to creative dancing. Thus, the relationship of AVPR1a to dance may reflect the significance of social relations and communication in dancing. The association of SLC64A with dance might date to the origins of dance in shamanism and related alterations of consciousness (see Garfinkel, 2018). Together, the two genes are likely involved in the emotional features of dance rather than sensorimotor integration and might predispose some individuals to excel in dance performance. Bachner-Melman et al. (2005) suggested that human dance is a form of courtship or social communication, which shares a conserved evolutionary history-characterized by common genetic and neurochemical mechanisms - with mating displays and affiliative behavior observed across vertebrates. An alternative approach to studying the genetics of dance consists in recognizing that-in human brains-dance, music, and speech rely on overlapping audio-motor networks (Fitch, 2016; Patel, 2010). Hence, inferences about the neurogenetics of human dance can be made from recent work on music (Gingras, Honing, Peretz, Trainor, \& Fisher, 2015; Järvelä, 2018; Niarchou et al., 2019; Ravignani, 2018) and speech (Graham \& Fisher, 2013).

\section{Dance and musicality}

Music and dance might have common roots in human evolution. Both are temporal sequences of pitches and movements and can be regarded as rhythmic movements (Wang, 2015). Pitch and rhythm are components in most forms of music, and the connection between music and the desire to move appears to be universal (Marcus, 2012). The production and perception of music are typically accompanied by and related to rhythmic movement (e.g., Repp, 2005; Phillips-Silver \& Trainor, 2005; Zatorre, Chen, \& Penhune, 2007; Maes, Leman, Palmer, \& Wanderley, 2014) and conceptually inseparable from dance and rituals in many cultures (Trehub, Becker, \& Morley, 2015).

Musicality is at the neurocognitive basis of music-related behavior and motor action. Musicality consists of many components, including perceptual capacities for detecting pitch and rhythm, motor capacities, and emotional or empathic capacities for anticipating others' reactions (Marcus, 2012). Thus, musicality may be a prerequisite not only for music and dance but also for spoken language given the common structural characteristics and neural circuits of music and speech (Masataka, 2009; Patel, 2003; Zatorre, Belin, \& Penhune, 2002). However, music and language diverge with regard to meaning, as music lacks" semanticity" (Trehub, 2003). The content conveyed in music is more emotional and non-declarative than in language. The same applies to dance, although it is not a vocal activity. Dance is a communicative process in which dancers convey information to the audience mainly via body movement (Orgs, Calvo-Merino, \& Cross, 2018; Orgs, Caspersen, \& Haggard, 2016). Like music (but unlike language), dance is better suited for the communication of emotional and non-declarative information. Dance can be differentiated from activities that include vocalization or sound-production by the predominance of body movement (i.e., dance is commonly not intended to produce an audible effect, but see Bläsing \& Zimmermann, submitted). Several brain areas are specialized for processing information from action observation. For example, the superior temporal sulcus (Blake \& Shiffrar, 2007; Vangeneugden, Peelen, Tadin, \& Battelli, 2014) plays a role in the perception of bodily expression of emotions (Grèzes, Adenis, Pouga, \& Armony, 2013) and the multisensory integration underlying auditory-motor interaction (Chen, Penhune, \& Zatorre, 2009; Kirsch, Dawson, \& Cross, 2015).

The use of auditory and visual (motor) information might be complementary and, therefore, advantageous in "noisy" (or competitive) settings as they may serve as mutual amplifiers. Athletes use complementary visual and auditory information to make domain-specific decisions in real-time (Allerdissen, Güldenpenning, Schack, \& Bläsing, 2017; Klein-Soetebier, Noël, \& Klatt, 2020). Evidence from research in birds suggests that facultative multimodal signaling may thwart eavesdropping by rivals (Smith, Taylor, \& Evans, 2011). Subordinate male fowls (Gallus gallus) switch from multimodal displays (movements and calls) to unimodal (silent) displays when the alpha male is attentive, independent of the hens' attention, suggesting that variation in signal type is influenced by social costs. Multimodal signaling is common for sexual traits and this has led to speculations about correlated evolution (see for review, Candolin, 2003), although recent evidence in birds suggests that courtship dance evolved independently from other traits (Gomes, Funghi, Soma, Sorenson, \& Cardoso, 2017). Similar speculations have been advanced for the relationship of static sexual traits in humans (i.e., facial and bodily features). The multiple fitness model (Cunningham, Roberts, Wu, Barbee, \& Druen, 1995) suggests that attractiveness varies across multiple dimensions, with each dimension representing a different aspect of mate value, whereas the redundant signaling hypothesis states that sexual traits may have an identical function and collectively improve signal reliability (Møller \& Pomiankowski, 1993). There is some support for the latter concerning female physical attractiveness (Grammer, Fink, Jütte, Ronzal, \& Thornhill, 2001). However, it is unclear whether the findings from the investigation of facial and body attractiveness extend to their dynamic representation and thus comprise a condition-dependent ornament of quality 
(for the relationship of face and voice attractiveness, see Valentova, Varella, Havlícek, \& Kleisne, 2017). If this was the case, we would expect positive correlations of voice attractiveness with dancing attractiveness/skills. Whether such relationships exist needs to be investigated in future studies.

Musicality may be a capacity underlying (spoken) language and dance, especially in a ritualistic form (Honing, 2018). However, the rhythmicity of music and dance is different from that of language and rituals. Considering their communicative functions, dance and ritualistic behavior can be discerned from language and music by the modality of signals (visual vs. auditory). The extent to which a signal is rhythmic may be a key difference between dance and music vs. language. Dance and music have a periodic component but are based on top-down inference and prediction, whereas the rhythmic regularity of spoken language may emerge from a cognitive process rather than being purely present in the signal (Jadoul, Ravignani, Thompson, Filippi, \& de Boer, 2016). We suggest that assessing comparative studies of dance-related behavior along the dimensions "visual vs. auditory" and "rhythmic vs. non-rhythmic" may help identify mechanisms in animal behavior relevant for understanding human dance musicality. Some birds, for example, perform vocal displays (songs) while engaging in elaborate, acrobatic motor displays (Ota, Gahr, \& Soma, 2015; Ota, Gahr, \& Soma, 2018). Likewise, different species of seals perform percussive displays by slapping their flippers on the water (Wahlberg, Lunneryd, \& Westerberg, 2002) or loudly clapping underwater (Hocking et al., 2020). It will be important to identify which aspects of these and related reports might be informative for addressing the origin of human dance.

\section{Conclusions and future directions}

Anthropological and ethnographic documentation of dance across societies illustrate its cultural diversity and contextual influence. From a Darwinian perspective, dance should be adaptive when displaying certain capacities or skills produces benefits for the performer; we might hypothesize that a good dancer has higher reproductive success in environments that most closely resemble those we inhabited ancestrally. Whether this is the case remains to be investigated. Empirical studies focusing on solo dance performance suggest that, consistent with the sexual selection hypothesis, certain qualities (such as male physical strength; Weege, Pham, et al., 2015) are positively related in assessments of a dancer. Individual dance performances may have been used to assess mating-related qualities, similar to what is known from the display of motor performance in other species. Dancing in groups requires additional skills, although we do not propose that these are mutually exclusive of those that play a role in mating.

Dancing together with others is characterized by the coordination of individual performances, often accompanied by an external rhythm, and regarding its social function, it may be the cooperative activity that distinguishes human dance from non-human animal motor performance. An individual's ability to coordinate body movements with others and to a rhythm may provide credible social information about the ability and willingness to coordinate with others in addition to providing information about the individual's mating-related qualities derived from sensorimotor skills. Because of its artistic character and the difficulty of displaying "good" performance, we suggest that humans have been selected to use dance to communicate socially relevant information, as it comprises the least ambiguous form of sharing social information, including information about intentions and a common goal. When this occurred in evolution is speculative. However, recent research has documented physiological benefits from synchronizing body movements (such as increased pain threshold), which may have facilitated the practice of dance in groups and thus social bonding once it occurred (Tarr et al., 2016; Tarr, Launay, Cohen, \& Dunbar, 2015).

Garfinkel (2018) contended that the evolution of dance is closely related to the evolution of rituals, and that earlier in our evolutionary past, dance was an individual activity associated with courtship and mating because of the connections between dance and sexuality (Hanna, 2010). Later, dance was implemented into rituals and ceremonies and moved from the individual to the group level. According to this view, the original function of "dance" was courtship, with the functions of group coordination and the benefits from social cohesion emerging later. We consider this plausible (although difficult to test) given the similarities of motor performance as part of ritualization in non-human animals and humans. Ritualization is proposed to make signals more prominent, distinctive, and unambiguous; thus, they attract attention. Dissanayake (2006) noted that human ritual ceremony has parallels with the biological display of ritualized signals in that it includes behaviors from other social contexts and recombines them into distinctive displays. The ceremonial displays become ritualized to the extent that they include a repertoire of behaviors and establish a formalized framework of interaction to which participants conform (see also Watanabe \& Smuts, 1999). This process facilitated the diversification of social information conveyed through body movements given the human ability to experiment with displays and alter them intentionally. It is unclear when these processes started, although a stepwise implementation of dancing into various social settings is likely. The benefits associated with the display of dance movements, individually and in a group, were probably crucial in further employing dance as a vehicle for communication of credible social information.

Central questions in this context include the adaptive nature of dance performances, and whether certain skills are uniquely human or shared with other species. Drawing analogs between human dance and dance (-like) behavior in animals is tempting in the search for the origins of human dance. Eventually, analogy must be distinguished from homology when considering the evolutionary origin of a trait, as only the latter informs about inheritance and shared ancestry. Although we contend (cf. Miller, 2000) that phylogenetic information is not required to advance an adaptationist approach to human dance, the study of dance (-like) behavior across species has been ambiguous, especially with regard to terminology. Verbal descriptions and ethnographic/dance notation systems have limitations in capturing the variety and complexity of dance, including its social-contextual elements. With advances in digital movement recording, researchers today are better equipped with tools that facilitate the systematic assessment of human dance (Boucher, 2011; Himberg \& Thompson, 2014; Karreman, 2015). However, the application of these technologies in fieldwork remains challenging, and its use has mainly been limited to experimental, laboratory-based studies, with novel approaches emerging from crossdisciplinary research (Leach, 2014).

The majority of evolutionary psychological studies of dance in the mating context have focused on individual dance performances and include participants from only a few industrialized societies, both as dancers and observers. It is not known whether these findings generalize to other countries/societies, including pre-industrialized societies. The investigation of cross-cultural similarities in, for example, kinematic characteristics linked to specific expressions in dance, as well as variation in dance movement perception attributable to culture-dependent preferences are topics for future research. Variation in socio-cultural development and settings may be responsible for a society-specific emphasis of certain individual qualities that are conveyed through dancing or derived from dance. From a technological viewpoint, conducting research in this area may be difficult, as the setup of technology used in laboratory studies (i.e., motion capturing) is challenging in fieldwork. However, researchers can use existing stimuli from archived material in movement analysis and perception studies (Aristidou, Shamir, \& Chrysanthou, 2019). One of the advantages of motion-captured dance movements is that the motion information can be assessed independently of other physical properties of the dancer; thus, this technology removes information that could affect assessments by focusing on kinematic characteristics that can be used to explain preferences. A preferable scenario would be to collect (motion-captured) dance recordings from members of both small-scale and Western societies and 
present them to members of the other societies. In addition, accelerometer, goniometer, and gyroscope records (e.g., Großhauser, Bläsing, Spieth, \& Hermann, 2012; Thiel, Quandt, Carter, \& Moyle, 2014) are simple and cost-effective alternatives to optical motion capture systems to secure movement data in routine fieldwork. Likewise, the use of quantized displays affords an alternative technique for the study of the effect of human movement on social perception (Berry, Kean, Misovich, \& Baron, 1991).

From a Darwinian viewpoint, the evolution of a complex behavior should offer certain benefits for the individual. These benefits can be manifold and may have been reinforced with group benefits over time. Thus, independent of the questions about the mechanisms that evolved to facilitate human dance, we suggest that the accurate assessment of mating-related information was one of the primary concerns of ancestral humans that made dance popular across societies. Because dance offers a credible exchange of social information, humans may have adopted it in various contexts that were evolutionarily advantageous at both the individual and the group levels. Questions about the functions and mechanisms of dance evolution remain challenges for future research. We contend that a comparative approach may advance finding answers to questions about this conspicuous human universal display.

\section{Acknowledgments}

We thank the editor and two anonymous reviewers for their thoughtful comments and suggestions on a previous version of the manuscript. Part of the preparation of this article was conducted during the stay of one author (BF) at the Hanse-Wissenschaftskolleg in Delmenhorst (Germany) and a related workshop held at that location.

\section{References}

Albers, E. H., Karom, M., \& Smith, D. (2002). Serotonin and vasopressin interact in the hypothalamus to control communicative behavior. Neuroreport, 13(7), 931-933.

Allerdissen, M., Güldenpenning, I., Schack, T., \& Bläsing, B. (2017). Recognizing fencing attacks from auditory and visual information: A comparison between expert fencers and novices. Psychology of Sport and Exercise, 31, 123-130.

Apalkova, Y., Butovskaya, M. L., Bronnikova, N., Burkova, V., Shackelford, T. K., \& Fink, B. (2018). Assessment of male physical risk-taking behavior in a sample of Russian men and women. Evolutionary Psychological Science, 4(3), 314-321.

Århem, K. (1985). Pastoral Man in the Garden of Eden: The Maasai of the Ngorongoro Conservation Area, Tanzania, Uppsala. Uppsala: University of Uppsala, Department of Cultural Anthropology in cooperation with The Scandinavian Institute of African Studies.

Aristidou, A., Shamir, A., \& Chrysanthou, Y. (2019). Digital dance ethnography: Organizing large dance collections. Journal on Computing and Cultural Heritage, 12(4), $1-27$.

Bachner-Melman, R., Dina, C., Zohar, A. H., Constantini, N., Lerer, E., Hoch, S., ... Ebstein, R. P. (2005). AVPR1a and SLC6A4 gene polymorphisms are associated with creative dance performance. PLoS Genetics, 1(3), Article e42.

Barrett, H. C., Todd, P. M., Miller, G. F., \& Blythe, P. W. (2005). Accurate judgments of intention from motion cues alone: A cross-cultural study. Evolution and Human Behavior, 26(4), 313-331.

Barske, J., Schlinger, B. A., Wikelski, M., \& Fusani, L. (2011). Female choice for male motor skills. Proceedings of the Royal Society of London, Series B: Biological Sciences, 278(1724), 3523-3528.

Berry, D. S., Kean, K. J., Misovich, S. J., \& Baron, R. M. (1991). Quantized displays of human movement: A methodological alternative to the point-light display. Journal of Nonverbal Behavior, 15(2), 81-97.

Blake, R., \& Shiffrar, M. (2007). Perception of human motion. Annual Review of Psychology, 58, 47-73.

Bläsing, B., Calvo-Merino, B., Cross, E. S., Jola, C., Honisch, J., \& Stevens, C. J. (2012). Neurocognitive control in dance perception and performance. Acta Psychologica, 139 (2), 300-308.

Bläsing, B. \& Zimmermann, E. (submitted). Dance is more than meets the eye - how can dance performance be made accessible for a non-sighted audience? Frontiers in Psychology.

Borg, J., Andrée, B., Soderstrom, H., \& Farde, L. (2003). The serotonin system and spiritual experiences. American Journal of Psychiatry, 160(11), 1965-1969.

Boucher, M. (2011). Virtual dance and motion-capture. Contemporary aesthetics, 9.

Buss, D. M., \& Schmitt, D. P. (1993). Sexual strategies theory: An evolutionary perspective on human mating. Psychological Review, 100(2), 204-232.

Buss, D. M., \& Schmitt, D. P. (2019). Mate preferences and their behavioral manifestation. Annual Review of Psychology, 70, 77-110.

Byers, J., Hebets, E., \& Podos, J. (2010). Female mate choice based upon male motor performance. Animal Behaviour, 79(4), 771-778.
Candolin, U. (2003). The use of multiple cues in mate choice. Biological Reviews, 78(4), 575-595.

Charnavel, I. (2019). Steps toward a universal grammar of dance: Local grouping structure in basic human movement perception. Frontiers in Psychology, 10, 1364.

Chen, J. L., Penhune, V. B., \& Zatorre, R. J. (2008). Listening to musical rhythms recruits motor regions of the brain. Cerebral Cortex, 18(12), 2844-2854.

Chen, J. L., Penhune, V. B., \& Zatorre, R. J. (2009). The role of auditory and premotor cortex in sensorimotor transformations. Annals of the New York Academy of Sciences, $1169,15-34$.

Christensen, J. F., Cela-Conde, C. J., \& Gomila, A. (2017). Not all about sex: Neural and biobehavioral functions of human dance. Annals of the New York Academy of Sciences, 1400, 8-32.

Clayton, M. (2012). What is entrainment? Definition and applications in musical research. Empirical Musicology Review, 7(1-2), 49-56.

Cunningham, M. R., Roberts, A. R., Wu, C.-H., Barbee, A. P., \& Druen, P. B. (1995). Their ideas of beauty are, on the whole, the same as ours: Consistency and variability in the cross-cultural perception of female attractiveness. Journal of Personality and Social Psychology, 68(2), 261-279.

De Gelder, B. (2006). Towards the neurobiology of emotional body language. Nature Reviews Neuroscience, 7(3), 242-249.

Dissanayake, E. (2006). Ritual and ritualization: Musical means of conveying and shaping emotion in humans and other animals. In S. Brown, \& U. Voglsten (Eds.), Music and manipulation: On the social uses and social control of music (pp. 31-56). Oxford, New York: Berghahn Books.

Dittrich, W., \& Lea, S. (1994). Visual perception of intentional motion. Perception, 23(3), 253-268.

Dittrich, W. H., Troscianko, T., Lea, S. E., \& Morgan, D. (1996). Perception of emotion from dynamic point-light displays represented in dance. Perception, 25(6), 727-738.

Dunbar, R. I. M. (2012). On the evolutionary function of song and dance. In N. Bannan, \& S. Mithen (Eds.), Music, language, and human evolution (pp. 201-214). Oxford: Oxford University Press.

Dunbar, R. I. M., Kaskatis, K., MacDonald, I., \& Barra, V. (2012). Performance of music elevates pain threshold and positive affect: Implications for the evolutionary function of music. Evolutionary Psychology, 10(4), 688-702.

Dunbar, R. I. M., \& Schultz, S. (2010). Bondedness and sociality. Behavior, 147(7), $775-803$.

Eibl-Eibesfeldt, I. (1984). Die Biologie des menschlichen Verhaltens: Grundriss der Humanethologie. München: Piper.

Ellamil, M., Berson, J., Wong, J., Buckley, L., \& Margulies, D. S. (2016). One in the Dance: Musical correlates of group synchrony in a real-world club environment. PLoS One, 11(10), Article e0164783.

Fessler, D. M. T., \& Holbrook, C. (2014). Marching into battle: Synchronized walking diminishes the conceptualized formidability of an antagonist in men. Biology Letters, 10(8), 20140592.

Fink, B., Hugill, N., \& Lange, B. P. (2012). Women's body movements are a potential cue to ovulation. Personality and Individual Differences, 53(6), 759-763.

Fink, B., Neave, N., \& Seydel, H. (2007). Male facial appearance signals physical strength to women. American Journal of Human Biology, 19(1), 82-87.

Fink, B., Weege, B., Neave, N., Pham, M. N., \& Shackelford, T. K. (2015). Integrating body movement into attractiveness research. Frontiers in Psychology, 6, 220.

Fink, B., Weege, B., Neave, N., Ried, B., \& do Lago, O. C. (2014). Female perceptions of male body movement (pp. 299-324). In V. Weekes-Shackelford, \& T. K. Shackelford (Eds.), Evolutionary perspectives on human sexual psychology and behavior. Berlin, Heidelberg: Springer.

Fitch, W. T. (2015). Four principles of bio-musicality. Philosophical Transactions of the Royal Society of London B, 370(1664), 20140091.

Fitch, W. T. (2016). Dance, music, meter and groove: A forgotten partnership. Frontiers in Human Neuroscience, 10, 64.

Fowler, C. A., Richardson, M. J., Marsh, K. L., \& Shockley, K. D. (2008). Language use, coordination, and the emergence of cooperative action. In A. Fuchs, \& V. K. Jirsa (Eds.), Coordination: neural, behavioral and social dynamics (pp. 261-279). Berlin: Springer.

Francis, S. T. (1991). The origins of dance: the perspective of primate evolution. Dance Chronicle, 14, 203-220.

Fusani, L., Barske, J., Day, L. D., Fuxjager, M. J., \& Schlinger, B. A. (2014). Physiological control of elaborate male courtship: Female choice for neuromuscular systems. Neuroscience \& Biobehavioral Reviews, 46(4), 534-546.

Gangestad, S. W., \& Thornhill, R. (2008). Human oestrus. Proceedings of the Royal Society of London, Series B: Biological Sciences, 275(1638), 991-1000.

Garfinkel, Y. (2018). The evolution of human dance: Courtship, rites of passage, trance, calendrical ceremonies and the professional Dancer. Cambridge Archaeological Journal, 28(2), 283-298.

Gingras, B., Honing, H., Peretz, I., Trainor, L. J., \& Fisher, S. E. (2015). Defining the biological bases of individual differences in musicality. Philosophical Transactions of the Royal Society of London. Series B, Biological Sciences, 370, 1664, 20140092.

Gomes, A. C. R., Funghi, C., Soma, M., Sorenson, M. D., \& Cardoso, G. C. (2017). Multimodal signalling in estrildid finches: Song, dance and colour are associated with different ecological and life-history traits. Journal of Evolutionary Biology, 30(7), 1336-1346.

Graham, S. A., \& Fisher, S. E. (2013). Decoding the genetics of speech and language. Current Opinion in Neurobiology, 23(1), 43-51.

Grahn, J. A., \& Brett, M. (2007). Rhythm and beat perception in motor areas of the brain. Journal of Cognitive Neuroscience, 19(5), 893-906.

Grammer, K., Fink, B., Jütte, A., Ronzal, G., \& Thornhill, R. (2001). Female faces and bodies: N-dimensional feature space and attractiveness. In G. Rhodes, \& L. Zebrowitz 
(Eds.), Advances in Visual Cognition. Volume I: Facial Attractiveness (pp. 97-125). Ablex Publishing.

Grammer, K., Fink, B., Møller, A. P., \& Thornhill, R. (2003). Darwinian aesthetics: Sexual selection and the biology of beauty. Biological Reviews, 78(3), 385-407.

Grammer, K., Keki, V., Striebel, B., Atzmueller, M., \& Fink, B. (2003). Bodies in motion: A window to the soul? In E. Voland, \& K. Grammer (Eds.), Evolutionary Aesthetics (pp. 295-323). Berlin, Heidelberg: Springer.

Grèzes, J., Adenis, M. S., Pouga, L., \& Armony, J. L. (2013). Self-relevance modulates brain responses to angry body expressions. Cortex, 49(8), 2210-2220.

Großhauser, T., Bläsing, B., Spieth, C., \& Hermann, T. (2012). Wearable sensor-based real-time sonification of motion and foot pressure in dance teaching and training. Journal of the Audio Engineering Society, 60(7/8), 580-589.

Hagen, E. H., \& Bryant, G. A. (2003). Music and dance as a coalition signaling system. Human Nature, 14(1), 21-51.

Halina, M., Rossano, F., \& Tomasello, M. (2013). The ontogenetic ritualization of bonobo gestures. Animal Cognition, 16(4), 653-666.

Hanna, J. L. (1987). To dance is human: A theory of nonverbal communication. Chicago, London: University of Chicago Press.

Hanna, J. L. (2010). Dance and sexuality: Many moves. Journal of Sex Research, 47, 212-241.

Hanna, J. L., Abrahams, R. D., Crumine, N. R., Dirks, R., von Gizycki, R., Heyer, P., Wild, S. A. (1979). Movements toward understanding humans through the anthropological study of dance. Current Anthropology, 20(2), 313-379.

Hannon, E. E., Soley, G., \& Ullal, S. (2012). Familiarity overrides complexity in rhythmic perception: A cross-cultural comparison of American and Turkish listeners. Journal of Experimental Psychology: Human Perception and Performance, 38, 543-548.

Hasson, U., Nir, Y., Levy, I., Fuhrmann, G., \& Malach, R. (2004). Inter-subject synchronization of cortical activity during natural vision. Science, 303, 1634-1640.

Heider, F., \& Simmel, M. (1944). An experimental study in apparent behavior. The American Journal of Psychology, 57, 243-259.

Henderson, V. R., Hennessey, M., Barrett, D. W., Curtis, B., McCoy-Roth, M., Trentacoste, N., \& Fishbein, M. (2005). When risky is attractive: Sensation seeking and romantic partner selection. Personality and Individual Differences, 38(2), 311-325.

Himberg, T., \& Thompson, M. R. (2014). Learning and synchronising dance movements in South African songs - cross-cultural motion-capture study. Dance Research, 29, 305-328.

Hocking, D. P., Burville, B., Parker, W. M., Evans, A. R., Park, T., \& Marx, F. G. (2020). Percussive underwater signaling in wild gray seals. Marine Mammal Science, 36(2), 728-732.

Honing, H. (2018). Musicality as an upbeat to music: Introduction and research agenda. In H. Honing (Ed.), The origins of musicality (pp. 3-20). Cambridge, MA: MIT Press.

Hufschmidt, C., Weege, B., Röder, S., Pisanski, K., Neave, N., \& Fink, B. (2015). Physical strength and gender identification from dance movements. Personality and Individua Differences, 76, 13-17.

Hugill, N., Fink, B., \& Neave, N. (2010). The role of human body movements in mate selection. Evolutionary Psychology, 8, 66-89.

Hugill, N., Fink, B., Neave, N., Besson, A., \& Bunse, L. (2011). Women's perception of men's sensation seeking propensity from their dance movements. Personality and Individual Differences, 51(4), 483-487.

Hugill, N., Fink, B., Neave, N., \& Seydel, H. (2009). Men's physical strength is associated with women's perceptions of their dancing ability. Personality and Individual Differences, 47, 527-530.

Huxley, J. (1966). A discussion on ritualization of behavior in animals and man (Introduction). Philosophical Transactions of the Royal Society of London. Series B, Biological Sciences, 772(251), 247-271.

Insel, T. R., \& Young, L. J. (2001). The neurobiology of attachment. Nature Reviews Neuroscience, 2, 129-136.

Jadoul, Y., Ravignani, A., Thompson, B., Filippi, P., \& de Boer, B. (2016). Seeking temporal predictability in speech: Comparing statistical approaches on 18 world languages. Frontiers in Human Neuroscience, 10, 586.

Järvelä, I. (2018). Genomics studies on musical aptitude, music perception, and practice Annals of the New York Academy of Sciences, 1423(1), 82-91.

Karreman, L. (2015). Worlds of MoCap. Writing dance on a three-dimensional canvas. Performance Research, 20(6), 35-42.

Katz, J. H. (1976). A hypothesis about the uniqueness of natural language. Annals of the New York Academy of Sciences, 280(1), 33-41.

Kirsch, L. P., Dawson, K., \& Cross, E. S. (2015). Dance experience sculpts aesthetic perception and related brain circuits. Annals of the New York Academy of Sciences, 1337, 130-139.

Klein-Soetebier, T., Noël, B., \& Klatt, S. (2020). Multimodal perception in table tennis: The effect of auditory and visual information on anticipation and planning of action. International Journal of Sport and Exercise Psychology. https://doi.org/10.1080/ 1612197X.2020.1819370.

Knoblich, G., \& Sebanz, N. (2008). Evolving intentions for social interaction: From entrainment to joint action. Philosophical Transactions of the Royal Society B, 363, 363, 2021-2031.

Konvalinka, I., Xygalatas, D., Bulbulia, J., Schjødt, U., Jegindø, E. M., Wallott, S., Roepstorff, A. (2011). Synchronized arousal between performers and related spectators in a fire-walking ritual. Proceedings of the National Academy of Sciences USA, 108(20), 8514-8519.

Kurath, G. P. (1960). Panorama of dance ethnology. Current Anthropology, 1(3), 233-254.

Laland, K., Wilkins, C., \& Clayton, N. (2016). The evolution of dance. Current Biology, 26 (1), R5-R9.

Lange, R. (1975). The nature of dance. An anthropological perspective. London: MacDonald \& Evans.
Laver, J. (1964). Costume as the means of social aggression. In J. D. Cathy, \& F. J. Ebling (Eds.), The natural history of aggression (p. 101). London, New York: Academic Press.

Leach, J. (2014). Choreographic objects: Contemporary dance, digital creations and prototyping social visibility. Journal of Cultural Economy, 7(4), 458-475.

Little, A. C., Jones, B. C., \& DeBruine, L. M. (2011). Facial attractiveness: Evolutionary based research. Philosophical Transactions of the Royal Society, B: Biological Sciences, 366(1571), 1638-1659.

Lorenz, K. (1952). Über tanzähnliche Bewegungen bei Tieren. Studium Generale, 5(1), $1-9$.

Lorenz, K. (1966). Evolution of ritualization in the biological and cultural spheres. Philosophical Transactions of the Royal Society of London. Series B, Biological Sciences, 772(251), 273-284.

Maes, P.-J., Leman, M., Palmer, C., \& Wanderley, M. M. (2014). Action-based effects on music perception. Frontiers in Psychology, 4, 1008.

Marcus, G. F. (2012). Musicality: Instinct or acquired skill? Topics in Cognitive Science, 4, 498-512.

Masataka, N. (2009). The origins of language and the evolution of music: A comparative perspective. Physics of Life Reviews, 6, 11-22.

Maynard-Smith, J., \& Harper, D. (2003). Animal signals. Oxford: Oxford University Press.

McCarty, K., Darwin, H., Cornelissen, P. L., Saxton, T., Toveé, M. J., Caplan, N., \& Neave, N. (2017). Optimal asymmetry and other motion parameters that characterise high-quality female dance. Scientific Reports, 7, 42435.

McCarty, K., Hönekopp, J., Neave, N., Caplan, N., \& Fink, B. (2013). Male body movements as possible cues to physical strength: A biomechanical analysis. American Journal of Human Biology, 25(3), 307-312.

Mehr, S. A., Krasnow, M. M., Bryant, G. A., \& Hagen, E. (2020). Origins of music in credible signaling. Behavioral and Brain Sciences, 1-41.

Miles, L. K., Nind, L. K., \& Macrae, C. N. (2009). The rhythm of rapport: Inter-personal synchrony and social perception. Journal of Experimental Social Psychology, 45(3), $585-589$.

Miller, G. (2000). Evolution of human music through sexual selection. In N. L. Wallin, B. Meerker, \& S. Brown (Eds.), The origins of music (pp. 329-360). Cambridge, MA: MIT Press.

Miller, G., Tybur, J. M., \& Jordan, B. D. (2007). Ovulatory cycle effects on tip earnings by lap dancers: Economic evidence for human estrus? Evolution and Human Behavior, 28 (6), 375-381.

Møller, A. P., \& Pomiankowski, A. (1993). Why have birds got multiple sexual ornaments? Behavioral Ecology and Sociobiology, 32(3), 167-176.

Morris, D. (1957). Typical intensity and its relation to the problem of ritualization. Behavior, 11(1), 1-12.

Müller, V., \& Lindenberger, U. (2011). Cardiac and respiratory patterns synchronize between persons during choir singing. PLoS One, 9, Article e107538.

Neave, N., McCarty, K., Freynik, J., Caplan, N., Hönekopp, J., \& Fink, B. (2011). Male dance moves that catch a woman's eye. Biology Letters, 7(2), 221-224.

Niarchou, M., Sathirapongsasuti, J. F., Jacoby, N., Bell, E., McArthur, E., Straub, P., .. Gordon, R. L. (2019). Unravelling the genetic architecture of musical rhythm. bioRxiv. https://doi.org/10.1101/836197.

Orgs, G., Calvo-Merino, B., \& Cross, E. S. (2018). Knowing dance or knowing how to dance? Sources of expertise in aesthetic appreciation of human movement. In B. Bläsing, M. Puttke, \& T. Schack (Eds.), The neurocognition of dance: mind, movement and motor skills (pp. 238-257). Abingdon: Routledge.

Orgs, G., Caspersen, D., \& Haggard, P. (2016). You watch, I move, it matters: Aesthetic communication in dance. In S. S. Obhi, \& E. S. Cross (Eds.), Cambridge social neuroscience. Shared representations: Sensorimotor foundations of social life (pp. 627-653). Cambridge: Cambridge University Press.

Ota, N., Gahr, M., \& Soma, M. (2015). Tap dancing birds: The multimodal mutual courtship display of males and females in a socially monogamous songbird. Scientific Reports, 5, 1-6.

Ota, N., Gahr, M., \& Soma, M. (2018). Couples showing off: Audience promotes both male and female multimodal courtship display in a songbird. Science Advances, 4. eaat4779.

Patel, A. D. (2003). Language, music, syntax and the brain. Nature Neuroscience, 6, 674-681.

Patel, A. D. (2010). Music, language, and the brain. Oxford: Oxford University Press.

Patel, A. D., \& Iversen, J. R. (2014). The evolutionary neuroscience of musical beat perception: The Action Simulation for Auditory Prediction (ASAP) hypothesis. Frontiers in Systems Neuroscience, 8, 57.

Phillips-Silver, J., Aktipis, C. A., \& Bryant, G. A. (2010). The ecology of entrainment: foundations of coordinated rhythmic movement. Music Perception, 28, 3-14.

Phillips-Silver, J., \& Keller, P. E. (2012). Searching for roots of entrainment and joint action in early musical interactions. Frontiers in Human Neuroscience, 6, 26.

Philips-Silver, J., \& Trainor, L. J. (2005). Feeling the beat: Movement influences infant rhythm perception. Science, 308, 1430.

Pika, S., Wilkinson, R., Kendrick, K. H., \& Vernes, S. C. (2018). Taking turns: Bridging the gap between human and animal communication. Proceedings of the Royal Society of London, Series B: Biological Sciences, 285, 1880, 20180598.

Pinker, S. (1997). How the mind works. New York: Norton.

Pisanski, K., \& Feinberg, D. R. (2019). Vocal attractiveness. In S. Frühholz, \& P. Belin (Eds.), The Oxford Handbook of Voice Perception (pp. 607-625). New York, NY: Oxford University Press.

Ravignani, A. (2017). Interdisciplinary debate: Agree on definitions of synchrony. Nature, 545, 158.

Ravignani, A. (2018). Darwin, sexual selection, and the origins of music. Trends in Ecology \& Evolution, 33(10), 716-719.

Ravignani, A., Bowling, D. L., \& Fitch, W. (2014). Chorusing, synchrony, and the evolutionary functions of rhythm. Frontiers in Psychology, 5, 1118. 
Ravignani, A., \& Cook, P. F. (2016). The evolutionary biology of dance without frills. Current Biology, 26, R878-R879.

Ravignani, A., \& Kotz, S. (2017). Evolution of temporal interaction: A comparative approach to social timing. PeerJ Preprints, 5, e3275v1.

Reddish, P., Fischer, R., \& Bulbulia, J. (2013). Let's dance together: Synchrony, shared intentionality and cooperation. PLoS One, 8, Article e71182.

Refsdal, A. S. (2017). Jump performance in Maasai jumpers and Caucasian controls. MA thesis in Sports Sciences. Norwegian School of Sports Sciences: Department of Physical Performance. Oslo.

Repp, B. H. (2005). Sensorimotor synchronization: A review of the tapping literature. Psychonomic Bulletin \& Review, 12(6), 969-992.

Roeder, S., Carbon, C.-C., Shackelford, T. K., Pisanski, K., Weege, B., \& Fink, B. (2015). Men's visual attention and perceptions of women's dance movements. Personality and Individual Differences, 101, 1-3.

Runeson, S., \& Frykholm, G. (1983). Kinematic specification of dynamics as an informational basis for person and action perception: Expectation, gender recognition and deceptive intention. Journal of Experimental Psychology: General, 112 (4), 580-610.

Sachs, C. (1937). World history of the dance. New York: W. W. Norton \& Co., Inc.

Sandler, W. (2018). The body as evidence for the nature of language. Frontiers in Psychology, 9, 1782.

Schirmer, A., Meck, W. H., \& Penney, T. B. (2016). The socio-temporal brain: Connecting people in time. Trends in Cognitive Sciences, 20(10), 760-772.

Scott, J. L., Kawahara, A. Y., Skevington, J. H., Yen, S. H., Sami, A., Smith, M. L., \& Yack, J. E. (2010). The evolutionary origins of ritualized acoustic signals in caterpillars. Nature Communications, 1, 4.

Sell, A., Lukazsweski, A. W., \& Townsley, M. (2017). Cues of upper body strength account for most of the variance in men's bodily attractiveness. Proceedings of the Royal Society of London, Series B: Biological Sciences, 284(1869), 20171819.

Shockley, K., Baker, A. A., Richardson, M. J., \& Fowler, C. A. (2007). Articulatory constraints on interpersonal postural coordination. Journal of Experimental Psychology: Human Perception and Performance, 33(1), 201-208.

Shockley, K., Santana, M. V., \& Fowler, C. A. (2003). Mutual interpersonal postural constraints are involved in cooperative conversation. Journal of Experimental Psychology: Human Perception and Performance, 29(2), 326-332.

Siegfried, W. (1988). Dance, the fuguitrive from of art - aesthetics as behavior. In I. Rentschler, B. Herzberger, \& D. Epstein (Eds.), Beauty and the brain (pp. 117-145). Basel: Birkhäuser.

Smith, C. L., Taylor, A., \& Evans, C. S. (2011). Tactical multimodal signalling in birds: Facultative variation in signal modality reveals sensitivity to social costs. Animal Behaviour, 82(3), 521-527.

Soma, M., \& Iwama, M. (2017). Mating success follows duet dancing in the Java sparrow. PLoS One, 12(3), Article e0172655.

Tarr, B., Launay, J., Cohen, E., \& Dunbar, R. (2015). Synchrony and exertion during dance independently raise pain threshold and encourage social bonding. Biology Letters, 11(10), 20150767.

Tarr, B., Launay, J., \& Dunbar, R. (2014). Music and social bonding: Self-other merging and neurohormonal mechanisms. Frontiers in Psychology, 5, 1096.

Tarr, B., Launay, J., \& Dunbar, R. (2016). Silent disco: Dancing in synchrony leads to elevated pain thresholds and social closeness. Evolution and Human Behavior, 37(5), 343-349.

Thiel, D. V., Quandt, J., Carter, S. J. L., \& Moyle, G. (2014). Accelerometer based performance assessment of basic routines in classical ballet. Procedia Engineering, 72, $14-19$.

Thoresen, J. C., Vuong, Q. C., \& Atkinson, A. P. (2012). First impression: Gait cues drive reliable trait judgements. Cognition, 124(3), 261-271.

Thornhill, R., \& Gangestad, S. W. (2008). The evolutionary biology of human female sexuality. Oxford: Oxford University Press.
Trehub, S. E. (2003). The developmental origins of musicality. Nature Neuroscience, 6, $669-673$.

Trehub, S. E., Becker, J., \& Morley, I. (2015). Cross-cultural perspectives on music and musicality. Philosophical Transactions of the Royal Society, Series B, Biological Sciences, 370(1664), 20140096.

Ullrich, R., Norton, P., \& Scharff, C. (2016). Waltzing Taeniopygia: Integration of courtship song and dance in the domesticated Australian zebra finch. Animal Behaviour, 112, 285-300.

van Ulzen, N. R., Lamoth, C. J., Daffertshofer, A., Semin, G. R., \& Beek, P. J. (2008). Characteristics of instructed and uninstructed interpersonal coordination while walking side-by-side. Neuroscience Letters, 432(2), 88-93.

Valentova, J. V., Varella, M. A., Havlíček, J., \& Kleisne, K. (2017). Positive association between vocal and facial attractiveness in women but not in men: A cross-cultural study. Behavioral Processes, 135, 95-100.

Vangeneugden, J., Peelen, M. V., Tadin, D., \& Battelli, L. (2014). Distinct neural mechanisms for body form and body motion discriminations. The Journal of Neuroscience, 34(2), 574-585.

Vicary, S., Sperling, M., Zimmermann, J.v., Richardson, D. C., \& Orgs, G. (2017). Joint action aesthetics. PLoS One, 12(7), Article e0180101.

Wahlberg, M., Lunneryd, S.-G., \& Westerberg, H. (2002). The source level of harbour seal flipper slaps. Aquatic Mammals, 28, 90-92.

Walk, R. D., \& Homan, C. P. (1984). Emotion and dance in dynamic light displays. Bulletin of the Psychonomic Society, 22(5), 437-440.

Wang, T. (2015). A hypothesis on the biological origins and social evolution of music and dance. Frontiers in Neuroscience, 9, 30.

Watanabe, J. M., \& Smuts, B. B. (1999). Explaining ritual without explaining it away: Trust, truth, and the evolution of cooperation in Roy A. Rappaport's "The obvious aspect of ritual". American Anthropologist, 101(1), 98-112.

Waterhouse, E., Watts, R., \& Bläsing, B. E. (2014). Doing Duo-a case study of entrainment in William Forsythe's choreography "Duo". Frontiers in Human Neuroscience, 8, 812.

Weege, B., Barges, L., Pham, M. N., Shackelford, T. K., \& Fink, B. (2015). Women's attractiveness perception of men's dance movements in relation to self-reported and perceived personality. Evolutionary Psychological Science, 1(1), 23-27.

Weege, B., Lange, B. P., \& Fink, B. (2012). Women's visual attention to variation in men's dance quality. Personality and Individual Differences, 53(3), 236-240.

Weege, B., Pham, M. N., Shackelford, T. K., \& Fink, B. (2015). Physical strength and dance attractiveness: Further evidence for an association in men, but not in women. American Journal of Human Biology, 27(5), 728-730.

Windhager, S., Schaefer, K., \& Fink, B. (2011). Geometric morphometrics of male facial shape in relation to physical strength and perceived attractiveness, dominance and masculinity. American Journal of Human Biology, 23(6), 805-814.

Witek, M. A. G., Clarke, E. F., Wallentin, M., Kringelbach, M. L., \& Vuust, P. (2014). Syncopation, body-movement and pleasure in groove music. PLoS One, 9, Article e94446.

Zahavi, A. (1980). Ritualization and the evolution of movement signals. Behaviour, 72(12), 77-81.

Zahavi, A., \& Zahavi, A. (1997). The handicap principle: A missing piece of Darwin's puzzle. New York, Oxford: Oxford University Press.

Zatorre, R. J., Belin, P., \& Penhune, V. B. (2002). Structure and function of auditory cortex: Music and speech. Trends in Cognitive Sciences, 6(1), 37-46.

Zatorre, R. J., Chen, J. L., \& Penhune, V. B. (2007). When the brain plays music: Auditory-motor interactions in music perception and production. Nature Reviews Neuroscience, 8, 547-558.

Zimmermann, J.v., Vicary, S., Sperling, M., Orgs, G., \& Richardson, D. C. (2018). The choreography of group affiliation. Topics in Cognitive Science, 10(1), 80-94. 